\title{
Short-Term Lung Function Changes and Predictors of Progressive Systemic Sclerosis- Related Interstitial Lung Disease
}

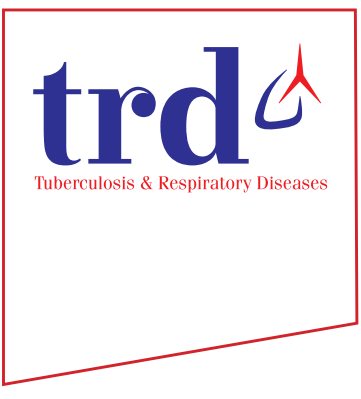

\author{
Punchalee Kaenmuang, M.D. (i) and Asma Navasakulpong, M.D. (1) \\ Respiratory and Respiratory Critical Care Medicine Unit, Division of Internal Medicine, Songklanagarind Hospital, Prince of \\ Songkla University, Hat Yai, Thailand
}

Background: Systemic sclerosis (SSc) involves multiple organ systems and has the highest mortality among connective tissue diseases. Interstitial lung disease is the most common cause of death among SSc patients and requires closer studies and follow-ups. This study aimed to identify lung function changes and predictors of progressive disease in systemic sclerosis-related interstitial lung disease (SSc-ILD).

Methods: A retrospective study extracted SSc patients from an electronic database January 2002-July 2019. Eligible cases were SSc patients >age 15 diagnosed with SSc-ILD. Factors associated with progressive disease were analyzed by univariate and multivariate logistic regression analyses.

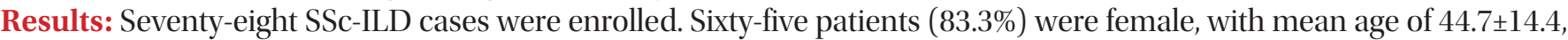
and 50 (64.1\%) were diffuse type SSc-ILD. Most SSc-ILD patients had crackles (75.6\%) and dyspnea on exertion (71.8\%), and $19.2 \%$ of the SSc-ILD patients had no abnormal respiratory symptoms but had abnormal chest radiographic findings. The most common diagnosis of SSc-ILD patients was non-specific interstitial pneumonia (43.6\%). The lung function values of diffusing capacity of the lung for carbon monoxide (DLCO) and DLCO per unit alveolar volume declined in progressive SSc-ILD during a 12-month follow-up. Male and no previous aspirin treatment were the two significant predictive factors of progressive SSc-ILD with adjusted odds ratios of 5.72 and 4.99, respectively.

Conclusion: This present study showed that short-term lung function had declined during the 12-month follow-up in progressive SSc-ILD. The predictive factors in progressive SSc-ILD were male sex and no previous aspirin treatment. Close follow-up of the pulmonary function tests is necessary for early detection of progressive disease.

Keywords: Lung Function Parameters; Predictive Factors; Systemic Sclerosis-Related Interstitial Lung Disease

\section{Address for correspondence: Asma Navasakulpong, M.D.}

Respiratory and Respiratory Critical Care Medicine Unit, Division

of Internal Medicine, Songklanagarind Hospital, Prince of Songkla

University, Hat Yai, Songkhla 90110, Thailand

Phone: 66-74-451-474, Fax: 66-74-455-855

E-mail: navasakulpong@hotmail.com

Received: Apr. 27, 2020

Revised: Jun. 17, 2020

Accepted: Jul. 15, 2020

Published online: Jul. 15, 2020

(c) It is identical to the Creative Commons Attribution Non-Commercial License (http://creativecommons.org/licenses/by-nc/4.0/).

Copyright $\subset 2020$

The Korean Academy of Tuberculosis and Respiratory Diseases.

\section{Introduction}

Systemic sclerosis (SSc) is a connective tissue disease which involves multiple organ systems, such as the skin, pulmonary, renal, cardiovascular, and gastrointestinal systems. SSc also has the highest mortality of all the connective tissue diseases ${ }^{1}$. The course of SSc is progressive and has poor survival outcomes. In a French cohort, the overall survival rates at 1, 3, 5, and 10 years from diagnosis were $98.0 \%, 92.5 \%, 85.9 \%$, and $71.7 \%$ respectively ${ }^{2}$. Pulmonary and renal involvement are the two leading causes of death. Systemic sclerosis-related interstitial lung disease (SSc-ILD) is the most common cause of death in SSc $(33 \%)^{2,3}$.

SSc-ILD is a fibrotic lung disease which has a devastating effect on the lives of SSc patients; therefore, determining the 
time to initiate treatment is crucial. The pathogenesis of SScILD remains unclear; however, three steps of pathogenesis have been proposed: (1) persistent and repeated injuries of endothelial cells; (2) activation of innate/adaptive immunity; and (3) fibroblast recruitment/activation ${ }^{4}$. From previous studies, the associated factors of lung function decline in SScILD are black males, diffuse type, and presence of antinuclear antibodies, anti-topoisomerase I, and anti-Th/To, but the absence of anti-centromere antibodies ${ }^{4-12}$.

Pulmonary function test (PFT) results in early SSc-ILD are likely to be in the normal range as mentioned by Degano et al. ${ }^{12}$. There are different patterns of lung function changes in SSc-ILD such as progression, stability, and improvement. The changes in dynamic lung function depend on the natural history, predictive factors, and previous treatments for SSc patients. Both forced vital capacity (FVC) and diffusion capacity of the lung for carbon monoxide (DLCO) are prognostic factors for mortality in SSc-ILD patients. Therefore, keeping close follow-up by performing PFTs should be done every 3-6 months in symptomatic patients and every 12 months in asymptomatic patients as proposed by Bauer et al. ${ }^{5}$.

Due to the limited number of studies regarding the predictive factors of interstitial lung disease (ILD) and the progression or patterns of lung function changes in SSc-ILD patients, we conducted this study to reveal the factors associated with the changes in lung function and short-term dynamic changes of lung function using FVC and DLCO at 1 year after diagnosis of SSc-ILD. These results could lead to an early diagnosis and provide data for the consideration of anti-fibrotic treatment in SSc-ILD.

\section{Materials and Methods}

\section{Study design and patients}

This retrospective study extracted SSc patients, using International Classification of Diseases, 10th revision (ICD10) codes M34, M34.0, M34.1, M34.2, M34.8, and M34.9 from the electronic-based health information system at Songklanagarind Hospital in southern Thailand from January 2002 to July 2019. All cases were reviewed by the authors. Eligible cases included patients are as follows: (1) >15 years old; (2) diagnosed with SSc according to the criteria described in the 2013 American College of Rheumatology/European League Against Rheumatism criteria $^{13}$ (EULAR/ACR) or the 1980 American College of Rheumatology classification criteria (ACR) for SSc for patients diagnosed before $2013^{14}$ by rheumatologists; and (3) diagnosed as SSc-ILD by pulmonologists according to the European respiratory society review $2015^{4}$. Participants who had not undergone a PFT or did not have a high-resolution computed tomography (HRCT) of the chest were excluded from the study.
Baseline demographics and characteristics of all participants, including SSc data, SSc-ILD data, HRCT findings, and PFT results at baseline (defined as PFT which was done within a month after diagnosis of SSc) and at 6- and 12-month followups, were collected by the original investigator. The PFTs were performed by a SensorMedics 6200 Autobox DL Respiratory Analyzer (SensorMedics Corporation A subsidiary of VIASYS Healthcare, Yorba Linda, CA, USA) from 2002-2007 and a SensorMedics VIASYS Vmax Encore 22+Auto Box V62J (SensorMedics Corporation) from 2008-2019. Participants who had lung function decline, defined as a decrease of $\mathrm{FVC} \geq 10 \%$ and/or DLCO $\geq 15 \%$ within 1 year after initial diagnosis of SScILD, were identified as progressive SSc-ILD.

This study was approved by the Human Research Ethics Committee (HREC) at the Faculty of Medicine, Prince of Songkhla University, Thailand (REC.62-299-14-1). The informed consent was waived because of the retrospective nature of the study.

\section{Statistical analysis}

Descriptive data are presented as mean \pm standard deviation (SD) or median $\left(Q_{1}-Q_{3}\right)$, or number with percent, based on the type of data. Continuous data, such as pulmonary function parameters and oxygen saturation, are presented as mean $\pm \mathrm{SD}$ or median $\left(Q_{1}-Q_{3}\right)$, whereas categorical data, such as sex, smoking status, type and clinical symptoms of SSc/SSc-ILD, HRCT findings, type of SSc-ILD, and previous medication are presented as number and percentage. Factors associated with progressive lung function change were analyzed by univariate

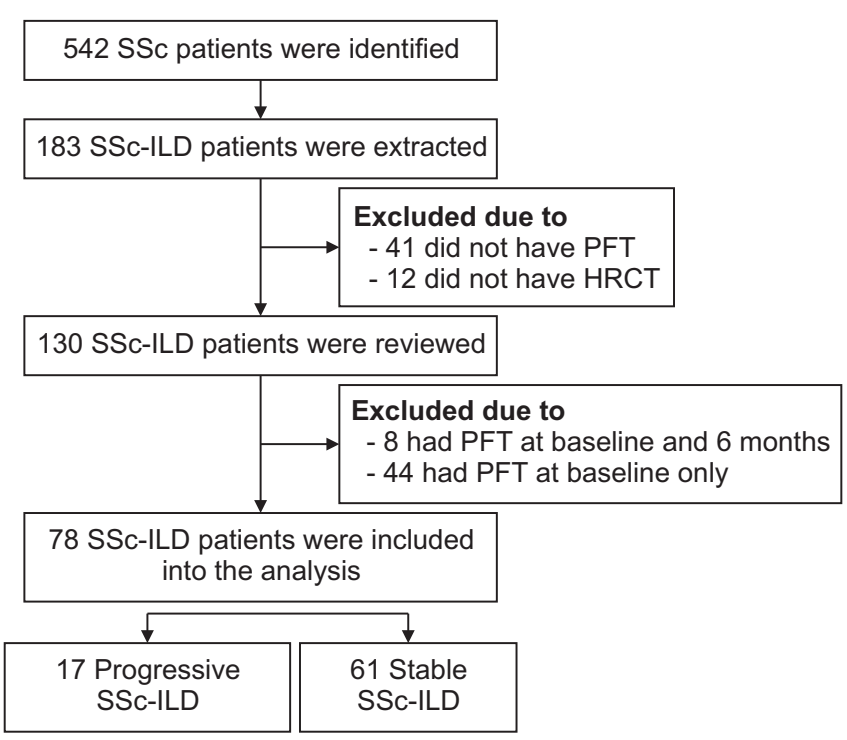

Figure 1. Flow chart of patient selection. SSc: systemic sclerosis; ILD: interstitial lung disease; PFT: pulmonary function test; HRCT: high-resolution computed tomography of chest. 
Table 1. Demographic and clinical characteristics of SSc at baseline

\begin{tabular}{|c|c|c|c|c|}
\hline Characteristic & $\begin{array}{c}\text { Total } \\
(n=78)\end{array}$ & $\begin{array}{c}\text { Progressive } \\
\text { SSc-ILD }(n=17)\end{array}$ & $\begin{array}{l}\text { Stable SSc-ILD } \\
\quad(n=61)\end{array}$ & p-value \\
\hline Female sex & $65(83.3)$ & $11(64.7)$ & $54(88.5)$ & 0.030 \\
\hline Age of onset SSc, yr & $44.7(14.4)$ & $43.3(14.3)$ & $45.1(14.5)$ & 0.661 \\
\hline Body mass index, $\mathrm{kg} / \mathrm{m}^{2}$ & $21.9(4)$ & $22.2(5)$ & $21.8(3.6)$ & 0.673 \\
\hline Smoking status & & & & 0.470 \\
\hline Current smokers & $2(2.6)$ & $1(5.9)$ & $1(1.6)$ & \\
\hline Former smokers & $7(9)$ & $2(11.8)$ & $5(8.2)$ & \\
\hline Non-smokers & $69(88.5)$ & $14(82.4)$ & $55(90.2)$ & \\
\hline Type of SSc & & & & $>0.99$ \\
\hline Diffuse & $50(64.1)$ & $11(64.7)$ & $39(63.9)$ & \\
\hline Limited & $28(35.9)$ & $6(35.3)$ & $22(36.1)$ & \\
\hline \multicolumn{5}{|c|}{ Clinical symptoms of SSc (mutually exclusive) } \\
\hline Raynaud phenomenon & $53(67.9)$ & $11(64.7)$ & $42(68.9)$ & 0.976 \\
\hline Digital ulcer & $10(12.8)$ & $1(5.9)$ & $9(14.8)$ & 0.446 \\
\hline Digital pitting scar & $50(64.1)$ & $9(52.9)$ & $41(67.2)$ & 0.424 \\
\hline Tendon friction rub & $1(1.3)$ & $1(5.9)$ & $0(0)$ & 0.218 \\
\hline Arthritis & $26(33.3)$ & $7(41.2)$ & $19(31.1)$ & 0.628 \\
\hline Joint contracture & $3(3.8)$ & $1(5.9)$ & $2(3.3)$ & 0.527 \\
\hline Dysphagia & $13(16.7)$ & $3(17.6)$ & $10(16.4)$ & $>0.99$ \\
\hline GERD & $32(41)$ & $6(35.3)$ & $26(42.6)$ & 0.791 \\
\hline Weakness & $5(6.4)$ & $1(5.9)$ & $4(6.6)$ & $>0.99$ \\
\hline \multicolumn{5}{|l|}{ Laboratory investigations } \\
\hline $\mathrm{eGFR}, \mathrm{mL} / \mathrm{min} / 1.73 \mathrm{~m}^{2}$ & $96(81-108)$ & $98(79-110)$ & $96(82.5-105.2)$ & 0.985 \\
\hline $\mathrm{CPK}, \mathrm{U} / \mathrm{L}$ & $108(52-269)$ & $99(71-1,080)$ & $115(46-259.2)$ & 0.339 \\
\hline $\mathrm{ESR}, \mathrm{mm} / \mathrm{hr}$ & $42(25-63.5)$ & $25(9.5-39)$ & $45.5(30-67)$ & 0.004 \\
\hline \multicolumn{5}{|l|}{ Serology } \\
\hline ANA & $76(97.4)$ & $16(94.1)$ & $60(98.4)$ & 0.391 \\
\hline \multicolumn{5}{|l|}{ ANA titer } \\
\hline $1: 80$ & $17(22.4)$ & $6(37.5)$ & $11(18.3)$ & \\
\hline $1: 160$ & $13(17.1)$ & 3 (18.8) & $10(16.7)$ & \\
\hline $1: 320$ & $12(15.8)$ & $1(6.2)$ & $11(18.3)$ & \\
\hline $1: 640$ & $11(14.5)$ & $2(12.5)$ & $9(15.0)$ & \\
\hline$\geq 1: 1,280$ & $23(30.3)$ & $4(25.0)$ & $19(31.7)$ & \\
\hline Anti-scl-70 & $35(44.9)$ & $7(41.2)$ & $28(45.9)$ & 0.944 \\
\hline Anti-centromere & $3(3.8)$ & $0(0)$ & $3(4.9)$ & $>0.99$ \\
\hline Anti-Sm & $6(7.7)$ & $0(0)$ & $6(9.8)$ & 0.33 \\
\hline Anti-SS-A & $16(20.5)$ & $5(29.4)$ & $11(18.0)$ & 0.311 \\
\hline Anti-SS-B & $6(7.7)$ & $2(11.8)$ & $4(6.6)$ & 0.606 \\
\hline Anti-Ro & $14(17.9)$ & $4(23.5)$ & $10(16.4)$ & 0.491 \\
\hline Anti-Jo-1 & $3(3.8)$ & $0(0)$ & $3(4.9)$ & $>0.99$ \\
\hline
\end{tabular}


Table 1. Continued

\begin{tabular}{|c|c|c|c|c|}
\hline Characteristic & $\begin{array}{c}\text { Total } \\
(n=78)\end{array}$ & $\begin{array}{c}\text { Progressive } \\
\text { SSc-ILD }(n=17)\end{array}$ & $\begin{array}{l}\text { Stable SSc-ILD } \\
(n=61)\end{array}$ & p-value \\
\hline \multicolumn{5}{|l|}{ Symptoms of SSc-ILD (mutually exclusive) } \\
\hline Dry cough & $46(59.0)$ & $11(64.7)$ & $35(57.4)$ & 0.791 \\
\hline Dyspnea on exertion & $56(71.8)$ & $11(64.7)$ & $45(73.8)$ & 0.545 \\
\hline Fatigue & $42(53.8)$ & $10(58.8)$ & $32(52.5)$ & 0.849 \\
\hline Hemoptysis & $1(1.3)$ & $0(0)$ & $1(1.6)$ & $>0.99$ \\
\hline Crackles & $59(75.6)$ & $13(76.5)$ & $46(75.4)$ & $>0.99$ \\
\hline Asymptomatic & $15(19.2)$ & $4(23.5)$ & $11(18.0)$ & 0.729 \\
\hline Duration between SSc and SSC-ILD diagnosis, yr & $0.4(0.1-3.2)$ & $1.1(0.1-5.3)$ & $0.4(0.1-2)$ & 0.342 \\
\hline WHO functional class & & & & 0.590 \\
\hline I & $32(41.0)$ & $8(47.1)$ & $24(39.3)$ & \\
\hline II & $40(51.3)$ & $7(41.2)$ & $33(54.1)$ & \\
\hline III & $6(7.7)$ & $2(11.8)$ & $4(6.6)$ & \\
\hline \multicolumn{5}{|l|}{ HRCT } \\
\hline Ground glass opacity & $46(59.0)$ & $12(70.6)$ & $34(55.7)$ & 0.411 \\
\hline Fine reticulation & $60(76.9)$ & $15(88.2)$ & $45(73.8)$ & 0.331 \\
\hline Coarse reticulation & $43(55.1)$ & $7(41.2)$ & $36(59.0)$ & 0.302 \\
\hline Septal thickening & $58(74.4)$ & $14(82.4)$ & $44(72.1)$ & 0.536 \\
\hline Honeycombing & $36(46.2)$ & $6(35.3)$ & $30(49.2)$ & 0.436 \\
\hline Bronchiectasis & $43(55.2)$ & $8(47.1)$ & $35(57.4)$ & 0.213 \\
\hline Architectural distortion & $44(56.4)$ & $7(41.2)$ & $37(60.7)$ & 0.248 \\
\hline Nodule & $13(16.7)$ & $1(5.9)$ & $12(19.7)$ & 0.277 \\
\hline Lymphadenopathy & $11(14.1)$ & $1(5.9)$ & $10(16.4)$ & 0.439 \\
\hline Esophageal dilatation & 30 (38.5) & $4(23.5)$ & $26(42.6)$ & 0.25 \\
\hline \multicolumn{5}{|l|}{ Type of ILD } \\
\hline NSIP and fibrotic NSIP & $48(61.5)$ & $11(64.7)$ & $37(60.7)$ & 0.960 \\
\hline UIP & $30(38.5)$ & $6(35.3)$ & $24(39.3)$ & 0.983 \\
\hline Pulmonary hypertension & $18(23.1)$ & $4(23.5)$ & $14(23.0)$ & $>0.99$ \\
\hline \multicolumn{5}{|l|}{ Medication } \\
\hline Aspirin & $43(55.1)$ & $6(35.3)$ & $37(60.7)$ & 0.113 \\
\hline Nifedipine & $49(62.8)$ & $11(64.7)$ & $38(62.3)$ & $>0.99$ \\
\hline Cyclophosphamide & $15(19.2)$ & $4(23.5)$ & $11(18.0)$ & 0.729 \\
\hline Chloroquine & $34(43.6)$ & $7(41.2)$ & $27(44.3)$ & $>0.99$ \\
\hline Colchicine & $52(66.7)$ & $13(76.5)$ & $39(63.9)$ & 0.497 \\
\hline Methotrexate & $1(1.3)$ & $1(5.9)$ & $0(0)$ & 0.218 \\
\hline Azathioprine & $13(16.7)$ & $5(29.4)$ & $8(13.1)$ & 0.143 \\
\hline Prednisolone & $39(50.0)$ & $9(52.9)$ & $30(49.2)$ & $>0.99$ \\
\hline
\end{tabular}

Values are presented as number $(\%)$ or median $\left(\mathrm{Q}_{1}-\mathrm{Q}_{3}\right)$.

SSc: systemic sclerosis; GERD: gastroesophageal reflux disease; eGFR: estimated glomerular filtration rate; CPK: creatine phosphokinase; ESR: erythrocyte sedimentation rate; ANA: antinuclear antibody; SSc-ILD: systemic sclerosis-related interstitial lung disease; WHO: World Health Organization; HRCT: high-resolution computed tomography; ILD: interstitial lung disease; NSIP: non-specific interstitial pneumonia; UIP: usual interstitial pneumonia. 
and multivariate logistic regression analyses. The statistical analysis used the R 3.5.2 software (R Foundation for Statistical Computing, Vienna, Austria). A result was considered to be statistically significant if the $p$-value was $<0.05$.

\section{Results}

Initially, 542 SSc cases were reviewed from the hospital health information system using these ICD-10 codes: M34, M34.0, M34.1, M34.2, M34.8, and M34.9. One hundred and eighty-three SSc-ILD cases were extracted using the inclusion criteria. Forty-one SSc-ILD cases were excluded because of no PFT results and 12 cases were excluded because of no HRCT. One hundred and thirty SSc-ILD cases were reviewed. A total of 78 SSc-ILD cases who had complete PFT results during the 12-month follow-up period were enrolled into the study. They were assigned into two groups according to lung function decline. The first group of 17 patients $(21.79 \%)$ had progressive SSc-ILD. The second group of 61 patients $(78.21 \%)$ had stable SSc-ILD (Figure 1).

Demographic and clinical characteristics at baseline are presented in Table 1. Sixty-five patients (83.3\%) were female with a mean age of $44.7 \pm 14.4$ years, 69 patients (88.5\%)

Table 2. Pulmonary function test and oxygen saturation at baseline and 6- and 12-month follow-up

\begin{tabular}{|c|c|c|c|c|}
\hline Variable & $\begin{array}{c}\text { Total } \\
(n=78)\end{array}$ & $\begin{array}{c}\text { Progressive SSc-ILD } \\
(n=17)\end{array}$ & $\begin{array}{l}\text { Stable SSc-ILD } \\
(n=61)\end{array}$ & p-value \\
\hline \multicolumn{5}{|l|}{ Baseline } \\
\hline FVC\% predicted & $64.6 \pm 16.4$ & $70.8 \pm 19.2$ & $62.9 \pm 15.3$ & 0.078 \\
\hline TLC\% predicted & $75.7 \pm 16.8$ & $79.6 \pm 19.2$ & $74.6 \pm 16.1$ & 0.283 \\
\hline $\mathrm{FEV}_{1} / \mathrm{FVC}$ ratio, $\%$ & $85(81-89.8)$ & $85(82-92)$ & $85(81-89)$ & 0.549 \\
\hline $\mathrm{FEV}_{1}, \mathrm{~L}$ & $1.6 \pm 0.4$ & $1.7 \pm 0.5$ & $1.5 \pm 0.4$ & 0.159 \\
\hline $\mathrm{FEV}_{1} \%$ predicted & $65.2 \pm 16$ & $72.4 \pm 17.8$ & $63.2 \pm 15$ & 0.036 \\
\hline DLCO\% predicted & $45.7 \pm 17.2$ & $43.6 \pm 16.9$ & $46.2 \pm 17.3$ & 0.584 \\
\hline DLCO/VA\% predicted & $74.8 \pm 22.5$ & $72.1 \pm 19.5$ & $75.6 \pm 23.3$ & 0.568 \\
\hline $\mathrm{SpO}_{2}, \%$ & $96(95-98)$ & $96(95-96)$ & $96(95-98)$ & 0.084 \\
\hline \multicolumn{5}{|l|}{ 6-Month } \\
\hline FVC\% predicted & $65.7 \pm 16.7$ & $70.5 \pm 18.4$ & $64.4 \pm 16.1$ & 0.181 \\
\hline TLC\% predicted & $71 \pm 16.9$ & $71.4 \pm 14.5$ & $70.8 \pm 17.6$ & 0.902 \\
\hline $\mathrm{FEV}_{1} / \mathrm{FVC}$ ratio, $\%$ & $84(80-88.8)$ & $88(82-91)$ & $83(79-88)$ & 0.055 \\
\hline $\mathrm{FEV}_{1}, \mathrm{~L}$ & $1.6 \pm 0.4$ & $1.7 \pm 0.4$ & $1.5 \pm 0.4$ & 0.314 \\
\hline $\mathrm{FEV}_{1} \%$ predicted & $64.8 \pm 16.6$ & $70.2 \pm 15.2$ & $63.3 \pm 16.8$ & 0.13 \\
\hline DLCO $\%$ predicted & $46.3 \pm 18.6$ & $42.4 \pm 16.4$ & $47.3 \pm 19.1$ & 0.337 \\
\hline DLCO/VA\% predicted & $72.9 \pm 24.9$ & $65.4 \pm 26.4$ & $75.1 \pm 24.3$ & 0.157 \\
\hline $\mathrm{SpO}_{2}, \%$ & $96(95-97)$ & $96(95-96)$ & $96(95-97)$ & 0.073 \\
\hline \multicolumn{5}{|l|}{ 12-Month } \\
\hline FVC\% predicted & $68 \pm 14.6$ & $63.4 \pm 15.3$ & $69.7 \pm 14.1$ & 0.173 \\
\hline TLC\% predicted & $74.9 \pm 17.2$ & $69.4 \pm 17.2$ & $77 \pm 17$ & 0.159 \\
\hline $\mathrm{FEV}_{1} / \mathrm{FVC}$ ratio, $\%$ & $84(78.5-88)$ & $85.5(80.2-87.8)$ & $83(78-88)$ & 0.22 \\
\hline $\mathrm{FEV}_{1}, \mathrm{~L}$ & $1.6 \pm 0.4$ & $1.6 \pm 0.4$ & $1.7 \pm 0.4$ & 0.499 \\
\hline $\mathrm{FEV}_{1} \%$ predicted & $67 \pm 14$ & $64.1 \pm 15.1$ & $68.1 \pm 13.7$ & 0.365 \\
\hline DLCO\% predicted & $46.7 \pm 15.3$ & $39 \pm 16.8$ & $49.6 \pm 13.9$ & 0.026 \\
\hline DLCO/VA\% predicted & $73.7 \pm 21.2$ & $60.5 \pm 21$ & $78.7 \pm 19.3$ & 0.005 \\
\hline $\mathrm{SpO}_{2}, \%$ & $96(95-97)$ & $95(95-96)$ & $96(95-97)$ & 0.095 \\
\hline
\end{tabular}

Values are presented as mean \pm SD or median $\left(\mathrm{Q}_{1}-\mathrm{Q}_{3}\right)$.

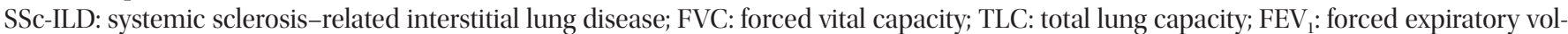
ume in 1 second; DLCO: diffusing capacity of the lung for carbon monoxide; DLCO/VA: diffusing capacity of the lung for carbon monoxide per unit alveolar volume; $\mathrm{SpO}_{2}$ : oxygen saturation. 
were non-smokers, and 50 patients (64.1\%) had diffuse type of SSc. The most common clinical symptoms of SSc were Raynaud phenomenon (67.9\%), digital pitting scar (64.1\%), gastroesophageal reflux disease (41\%), and arthritis (33.3\%). Most SSc-ILD patients had crackles $(75.6 \%)$ and dyspnea on exertion (71.8\%), while $19.2 \%$ of the SSc-ILD patients had no abnormal respiratory symptoms although they had abnormal chest radiography at the time of initial screening. The median duration between the diagnosis of SSc and SSc-ILD was 4 months. Thirty-five patients (44.9\%) had the presence of antiScl70 antibody. Anti-centromere was found in only three SSc-ILD patients (3.8\%). The most common type of SSc-ILD was nonspecific interstitial pneumonia (NSIP) and fibrotic NSIP (61.5\%), fibrotic NSIP defined as NSIP with evidence of fibrosis and bronchiectatic changed without honeycombing and no histopathology confirmation, and $23.1 \%$ of SSc-ILD patients also had pulmonary hypertension diagnosed by a mean pulmonary artery pressure more than $25 \mathrm{mmHg}$ from an echocardiogram. There were different baseline characteristics between the two groups. Although the majority of the progressive SSc-ILD patients were female, the statistical analysis revealed more males with progressive disease than in the stable group. Also, the progressive group had a lower median baseline erythrocyte sedimentation rate (ESR) than the stable SSc-ILD group.

Table 2 shows the dynamic PFT results in SSc-ILD patients during the 12-month follow-up period. At baseline, the mean FVC was $64.6 \% \pm 16.4 \%$ predicted and the mean DLCO was $45.7 \% \pm 17.2 \%$ predicted. Interestingly, the baseline forced expiratory volume in 1 second $\left(\mathrm{FEV}_{1}\right)$ was significantly higher in the progressive SSc-ILD group $(\mathrm{p}=0.036)$. However, there were no statistically significant differences in the other lung function parameters and oxygen saturation between the two groups at baseline and at the 6-month follow-up. At the 12-month follow-up in the progressive SSc-ILD group, the DLCO and DLCO per unit alveolar volume (DLCO/VA) val- ues were significantly decreased compared to the stable SScILD group ( $39.0 \pm 16.8$ vs. $49.6 \% \pm 13.9 \%$ predicted $[\mathrm{p}=0.026]$ and $60.5 \pm 21$ vs. $78.7 \% \pm 19.3 \%$ predicted $[\mathrm{p}=0.005]$, respectively).

In the progressive SSc-ILD group, the predictors of progression from univariate analysis (i.e., variables with p-values of $<0.2$ ) were included in the multivariate regression analysis to identify the predictors of progressive SSc-ILD (Table 3). The odds ratio of sex dropped from a univariate analysis odds ratio of 7.33 to 5.71 ( $\mathrm{p}=0.037)$ in the multivariate analysis. The odds ratios from the univariate and multivariate analyses interestingly increased for no previous aspirin treatment (4.99, $\mathrm{p}=0.030$ ). Median duration of aspirin used before developed SSc-ILD was 0.32 year. However, the ESR was a protecting factor for progressive disease with an adjusted odds ratio of 0.96 $(\mathrm{p}=0.021)$ in both the univariate and multivariate analyses.

\section{Discussion}

Pulmonary involvement in patients with SSc is related to poor prognosis and it is important to diagnose ILD quickly in order to intervene. However, detection is frequently delayed when the patient's illness develops gradually without symptoms such as dyspnea or cough and/or the typical findings in lung function test, or on HRCT. Our study investigated the clinical characteristics of patients with SSc accompanied by ILD and follow-up on lung function changes to identify the predictors suggesting some clues in progressive SSc-ILD.

The incidence of ILD is higher in patients with the diffuse type of SSc than in those with the limited type of SSc. In 3,656 patients with SSc, the European Scleroderma Trials and Research group ${ }^{6}$ reported that the incidence of ILD was $53 \%$ in patients with diffuse type SSc and 35\% in patients with the limited type. Our results for the incidence of ILD according to subtypes were similar. Our study had similar results to European, North American, and other studies done in Thailand

Table 3. Factors associated with progressive SSc-ILD by univariate and multivariate logistic regression analyses

\begin{tabular}{|lccc|}
\hline & $\begin{array}{c}\text { Crude OR } \\
(\mathbf{9 5 \%} \mathbf{C I})^{*}\end{array}$ & $\begin{array}{c}\text { Adjusted } \\
\text { OR (95\% CI) }\end{array}$ & p-value \\
\hline Male sex & $7.33(1.71-31.39)$ & $5.71(1.11-29.52)$ & $0.037^{*}$ \\
\hline No previous aspirin treatment & $3.33(0.98-11.32)$ & $4.99(1.17-21.3)$ & $0.030^{*}$ \\
\hline ESR & $0.96(0.93-0.99)$ & $0.96(0.93-0.99)$ & $0.021^{*}$ \\
\hline Smoking & $0.92(0.83-1.01)$ & - & $0.983^{\dagger}$ \\
\hline Azathioprine & $2.55(0.61-10.62)$ & - & $0.225^{\dagger}$ \\
$\mathrm{FEV}_{1}, \%$ of predicted & $0.96(0.92-1.00)$ & - & $0.547^{\dagger}$ \\
$\mathrm{FEV}_{1}, \mathrm{~L}$ & $0.29(0.06-1.49)$ & - & $0.683^{\dagger}$ \\
$\mathrm{FEV}_{1} / \mathrm{FVC}$ ratio, \% & $0.99(0.92-1.07)$ & & $0.798^{\dagger}$ \\
\hline
\end{tabular}

*Logistic regression analysis by the PLR test. ${ }^{\dagger}$ Logistic regression analysis by the Wald test.

SSc-ILD: systemic sclerosis-related interstitial lung disease; OR: odds ratio; CI: confidence interval; ESR: erythrocyte sedimentation rate; $\mathrm{FEV}_{1}$ : forced expiratory volume in 1 second; FVC: forced vital capacity. 
that found that SSc is found mostly in females ${ }^{8,10,11}$.

Pulmonary involvement was related to specific ethic, socioeconomic, and behavioral factors in $\mathrm{SSc}^{15}$. Patients with SSc with accompanying cardiopulmonary disease had frequent significant abnormalities on nailfold videocapillaroscopy ${ }^{9,16}$. This is consistent with the increased incidence of Raynaud phenomenon and digital pitting scar due to peripheral vascular abnormalities in patients with pulmonary involvement in our study. Surprisingly, digital ulcer was not different between the two groups of SSc which was different from the study by Jung et al. ${ }^{9}$. Therefore, clinicians should suspect pulmonary involvement if a patient with SSc has abnormal nailfold videocapillaroscopy patterns or Raynaud phenomenon and digital pitting scar.

In our study, we did not find a correlation between the specificity of autoantibodies and the progression of SSc-ILD which was contrary to a recent report ${ }^{17}$. On the other hand, the study from Jung et al. ${ }^{9}$ reported that SSc-ILD had higher positive values of anti-Scl70 antibody and lower positive values of anticentromere antibody compared to those without ILD. Also, the positivity of anti-Scl70 antibody was an independent risk factor for ILD in SSc patients ${ }^{16}$. However, that study did not show a correlation of these autoantibodies and the progression of SSc-ILD. Other studies demonstrated a strong association between anti-Scl70 antibody and ILD but did not show a strong association between autoantibodies and the progression of SSc-ILD ${ }^{18,19}$.

Our study revealed that most patients with SSc-ILD had crackles and dyspnea on exertion, whereas only a quarter had only abnormal chest radiography from screening. The most common type of SSc-ILD was NSIP which was similar to other studies ${ }^{9,20}$. The $\mathrm{FEV}_{1} \%$ predicted values at baseline were significantly higher in the progressive SSc-ILD group $(\mathrm{p}=0.036)$, whereas the DLCO and DLCO/VA values at 12 months in the progressive SSc-ILD group were significantly decreased compared to the stable SSc-ILD group (39.0 \pm 16.8 vs. $49.6 \% \pm 13.9 \%$ predicted $[\mathrm{p}=0.026]$ and $60.5 \pm 21$ vs. $78.7 \% \pm 19.3 \%$ predicted $[\mathrm{p}=0.005])$. FVC was quite stable at the 12-month follow-up in both groups. The significant predicting factors for the progression of SSc-ILD were male sex and patients who had not undergone previous aspirin treatment with adjusted odds ratios of 5.72 and 4.99 , respectively.

The baseline lung function test results of SSc-ILD patients at initial diagnosis in our study was different from other stud$\operatorname{ies}^{9,21-23}$; the mean of FVC was lower, whereas the DLCO was higher. These findings indicated that our patients had more severe restrictive defects, but less severe diffusion defects compared with previous studies. After the follow-up pulmonary function tests in the SSc-ILD patients in our study, overall, the FVC was stable after the 12-month follow-up which was quite similar to the study from Moore et al. ${ }^{22}$. However, due to our rather short 12-month follow-up time we did not find a change in the FVC that was reported in the Moore et al.'s study ${ }^{22}$ which conducted a 4-year follow-up and reported an annual rate of decline in FVC that was $0.08 \pm 3 \mathrm{~L} /$ year. Another study ${ }^{17}$ which followed SSc-ILD patients for $6.4 \pm 4.2$ years, found that during the follow-up, the FVC was stable while the DLCO significantly decreased $(-1.5 \pm 0.3 \% / \mathrm{yr}[\mathrm{p}<0.001])$.

First, we hypothesized that a significant FVC change $(\geq 10 \%)$ in a 12-month follow-up, though infrequently seen in SScILD patients, may still be a good predictor of its development. Second, our patients had a duration of only 4 months before the diagnosis. Therefore, it is possible that a change in the FVC may not be seen in the early stages of the disease. On the other hand, decrements greater than 15\% in DLCO and DLCO/VA in 12 months of follow-up were commonly found in SSc-ILD patients, especially in the progressive group which had the strongest positive predictive values, negative predictive values, and likelihood ratios for a poor outcome of SSc-ILD as reported in the previous study ${ }^{22}$. The threshold values for decline in FVC (10\%), DLCO (15\%), and DLCO/VA (15\%) that we used in our study were the same as those validated in idiopathic pulmonary fibrosis ${ }^{23,24}$. Although smaller declines in FVC and DLCO/VA are also predictive of outcome in ILD, this has not been replicated in SSc-ILD perhaps due to the slower rate of progression in the latter ${ }^{24}$. It is possible that even a smaller decline in lung function variables may be significant in SSc-ILD.

After we compared the progressive and stable SSc-ILD groups, the most significant factor associated with progressive SSc-ILD in our study were males who did not undergo previous aspirin treatment. As several studies have demonstrated, males were also more likely to have pulmonary involvement than females ${ }^{25,26}$. In previous studies, a hypothesis was put forward that in SSc-ILD patients who received previous aspirin treatment, aspirin causes generation of aspirin-triggered lipoxins and their 15-epimers which have anti-inflammatory and pro-resolution effect that lead to normal levels of lung resistance and elastance ${ }^{27,28}$. This mechanism leads to antifibrosis in SSc-ILD. We also found that ESR was a protecting factor for progressive disease since an elevated ESR indicates an inflammatory process. This finding might be from higher baseline ESR results that led the primary doctors to be concerned about the danger of SSc. Hence, they increased immunosuppressive agents to control the disease. In our study, we were unable to evaluate the effect of therapy on ILD outcomes because treatment assignment was not random and subject to confounding by indication.

Our study has some strengths and limitations. The first strength of our study is that this is only the second study, to our knowledge, which identified associated factors to predict progressive SSc-ILD. The first study by Wu et al. ${ }^{7}$ reported both lower $\mathrm{SpO}_{2}$ after the 6-minute walk test (6MWT) and arthritis as independent predictors for ILD progression. Unfortunately, the patients in our study did not perform the 6MWT but we were able to determine the simple predictors of progressive SSc-ILD. Second, our study also illustrated the 
demographic and clinical characteristics of SSc-ILD patients in Songklanagarind Hospital which could be a reflection of the population in southern Thailand. Last, our study was the first study in Thailand that performed full lung function testing that included the results of total lung capacity and DLCO at 12 months after SSc-ILD diagnosis to evaluate lung function changes of SSc-ILD patients.

We must also consider the limitations of our study. First, this study was a retrospective study in a single center. Therefore, we had some missing data, such as PFT at the 6- and 12-month follow-ups, because some SSc-ILD patients were unable to perform the PFT due to severe respiratory symptoms. Also, some patients had stable respiratory symptoms; therefore, most of the stable SSc-ILD patients were not scheduled for the PFT at 12 months. Second, a 12-month follow-up period was too short to detect changes in other lung function parameters for these patients.

This present study showed that short-term lung function changed at a 12-month follow-up date. A 1-year decline in either DLCO or DLCO/VA of $15 \%$ or more is a marker for a poor prognosis of progressive SSc-ILD. Male sex and no previous aspirin treatment were significant predictive factors in progressive SSc-ILD. Close monitoring and extending the duration of follow-up of the pulmonary function tests are necessary for the early detection and therapy of progressive SSCILD. The role of aspirin treatment should be further investigated.

\section{Authors' Contributions}

Conceptualization: Kaenmuang P. Methodology: Navasakulpong A. Formal analysis: Kaenmuang P, Navasakulpong A. Data curation: Kaenmuang P. Writing - original draft preparation: Kaenmuang P. Writing - review and editing: Navasakulpong A. Approval of final manuscript: all authors.

\section{Conflicts of Interest}

No potential conflict of interest relevant to this article was reported.

\section{Funding}

No funding to declare.

\section{References}

1. Elhai M, Meune C, Avouac J, Kahan A, Allanore Y. Trends in mortality in patients with systemic sclerosis over 40 years: a systematic review and meta-analysis of cohort studies. Rheumatology (Oxford) 2012;51:1017-26.

2. Pokeerbux MR, Giovannelli J, Dauchet L, Mouthon L, Agard C, Lega JC, et al. Survival and prognosis factors in systemic sclerosis: data of a French multicenter cohort, systematic review, and meta-analysis of the literature. Arthritis Res Ther 2019;21:86.

3. Barnes J, Mayes MD. Epidemiology of systemic sclerosis: incidence, prevalence, survival, risk factors, malignancy, and environmental triggers. Curr Opin Rheumatol 2012;24:16570.

4. Cappelli S, Bellando Randone S, Camiciottoli G, De Paulis A, Guiducci S, Matucci-Cerinic M. Interstitial lung disease in systemic sclerosis: where do we stand? Eur Respir Rev 2015;24:411-9.

5. Bauer PR, Schiavo DN, Osborn TG, Levin DL, St Sauver J, Hanson AC, et al. Influence of interstitial lung disease on outcome in systemic sclerosis: a population-based historical cohort study. Chest 2013;144:571-7.

6. Walker UA, Tyndall A, Czirjak L, Denton C, Farge-Bancel D, Kowal-Bielecka O, et al. Clinical risk assessment of organ manifestations in systemic sclerosis: a report from the EULAR Scleroderma Trials And Research group database. Ann Rheum Dis 2007;66:754-63.

7. Wu W, Jordan S, Becker MO, Dobrota R, Maurer B, Fretheim $\mathrm{H}$, et al. Prediction of progression of interstitial lung disease in patients with systemic sclerosis: the SPAR model. Ann Rheum Dis 2018;77:1326-32.

8. Wangkaew S, Euathrongchit J, Wattanawittawas P, Kasitanon $\mathrm{N}$, Louthrenoo W. Incidence and predictors of interstitial lung disease (ILD) in Thai patients with early systemic sclerosis: Inception cohort study. Mod Rheumatol 2016;26:588-93.

9. Jung E, Suh CH, Kim HA, Jung JY. Clinical characteristics of systemic sclerosis with interstitial lung disease. Arch Rheumatol 2018;33:322-7.

10. Bergamasco A, Hartmann N, Wallace L, Verpillat P. Epidemiology of systemic sclerosis and systemic sclerosis-associated interstitial lung disease. Clin Epidemiol 2019;11:257-73.

11. Unhapipatpong C, Mahakkanukrauh A, Foocharoen C, Suwannaroj S, Nanagara R, Tumsatan P. Pulmonary manifestation in systemic sclerosis in Srinagarind Hospital. J Med Assoc Thai 2018;101:213.

12. Degano B, Soumagne T, Eberst G, Meaux-Ruault N, Gil H, Magy-Bertrand N. Pulmonary function parameters other than vital capacity should be considered in screening for interstitial lung disease in patients with systemic sclerosis: comment on the article by Suliman et al. Arthritis Rheumatol 2016;68:2346-7.

13. van den Hoogen F, Khanna D, Fransen J, Johnson SR, Baron M, Tyndall A, et al. 2013 classification criteria for systemic sclerosis: an American College of Rheumatology/European League against Rheumatism collaborative initiative. Arthritis Rheum 2013;65:2737-47. 
14. Preliminary criteria for the classification of systemic sclerosis (scleroderma). Subcommittee for scleroderma criteria of the American Rheumatism Association Diagnostic and Therapeutic Criteria Committee. Arthritis Rheum 1980;23:581-90.

15. McNearney TA, Reveille JD, Fischbach M, Friedman AW, Lisse JR, Goel N, et al. Pulmonary involvement in systemic sclerosis: associations with genetic, serologic, sociodemographic, and behavioral factors. Arthritis Rheum 2007;57:31826.

16. Markusse IM, Meijs J, de Boer B, Bakker JA, Schippers HP, Schouffoer AA, et al. Predicting cardiopulmonary involvement in patients with systemic sclerosis: complementary value of nailfold videocapillaroscopy patterns and disease-specific autoantibodies. Rheumatology (Oxford) 2017;56:1081-8.

17. Le Gouellec N, Duhamel A, Perez T, Hachulla AL, Sobanski $\mathrm{V}$, Faivre JB, et al. Predictors of lung function test severity and outcome in systemic sclerosis-associated interstitial lung disease. PLoS One 2017;12:e181692.

18. Liaskos C, Marou E, Simopoulou T, Barmakoudi M, Efthymiou G, Scheper T, et al. Disease-related autoantibody profile in patients with systemic sclerosis. Autoimmunity 2017;50:414-21.

19. Graf SW, Hakendorf P, Lester S, Patterson K, Walker JG, Smith MD, et al. South Australian Scleroderma Register: autoantibodies as predictive biomarkers of phenotype and outcome. Int J Rheum Dis 2012;15:102-9.

20. Pandey AK, Wilcox P, Mayo JR, Sin D, Moss R, Ellis J, et al. Predictors of pulmonary hypertension on high-resolution computed tomography of the chest in systemic sclerosis: a retrospective analysis. Can Assoc Radiol J 2010;61:291-6.

21. Ryerson CJ, O'Connor D, Dunne JV, Schooley F, Hague CJ,
Murphy D, et al. Predicting mortality in systemic sclerosisassociated interstitial lung disease using risk prediction models derived from idiopathic pulmonary fibrosis. Chest 2015;148:1268-75.

22. Moore OA, Proudman SM, Goh N, Corte TJ, Rouse H, Hennessy $\mathrm{O}$, et al. Quantifying change in pulmonary function as a prognostic marker in systemic sclerosis-related interstitial lung disease. Clin Exp Rheumatol 2015;33(4 Suppl 91):S111-6.

23. Raghu G, Collard HR, Egan JJ, Martinez FJ, Behr J, Brown KK, et al. An official ATS/ERS/JRS/ALAT statement: idiopathic pulmonary fibrosis: evidence-based guidelines for diagnosis and management. Am J Respir Crit Care Med 2011;183:788824.

24. Zappala CJ, Latsi PI, Nicholson AG, Colby TV, Cramer D, Renzoni EA, et al. Marginal decline in forced vital capacity is associated with a poor outcome in idiopathic pulmonary fibrosis. Eur Respir J 2010;35:830-6.

25. Gilson M, Zerkak D, Wipff J, Dusser D, Dinh-Xuan AT, Abitbol $\mathrm{V}$, et al. Prognostic factors for lung function in systemic sclerosis: prospective study of 105 cases. Eur Respir J 2010;35:112-7.

26. Wells AU, Behr J, Silver R. Outcome measures in the lung. Rheumatology (Oxford) 2008;47 Suppl 5:v48-50.

27. Khanna D, Seibold JR, Wells A, Distler O, Allanore Y, Denton $\mathrm{C}$, et al. Systemic sclerosis-associated interstitial lung disease: lessons from clinical trials, outcome measures, and future study design. Curr Rheumatol Rev 2010;6:138-44.

28. Guilherme RF, Xisto DG, Kunkel SL, Freire-de-Lima CG, Rocco PR, Neves JS, et al. Pulmonary antifibrotic mechanisms aspirin-triggered lipoxin A(4) synthetic analog. Am J Respir Cell Mol Biol 2013;49:1029-37. 